\title{
PERENCANAAN SETTING PENGAMAN SALURAN UDARA TEGANGAN TINGGI 150 KV DENGAN DIBANGUNNYA GIS TANAH LOT
}

\author{
Anak Agung Ngurah Wanda Ariesta. ${ }^{1}$, I Gede Dyana Arjana. ${ }^{2}$, Tjok Gede Indra Partha ${ }^{3}$ \\ ${ }^{1,2,3}$ Program Studi Teknik Elektro, Fakultas Teknik, Universitas Udayana \\ Email : wandaariesta6@gmail.com ${ }^{1}$, dyanaarjana@unud.ac.id ${ }^{2}$, cokindra@ee.unud.ac.id ${ }^{3}$
}

\begin{abstract}
Abstrak
Dalam upaya untuk meningkatkan supply listrik PT.PLN (Persero) membangun GIS Tanah Lot di Desa Nyitdah Kabupaten Tabanan. Pembangunan GIS baru membuat jaringan sistem transmisi Saluran Udara Tegangan Tinggi $150 \mathrm{kV}$ berubah. Perubahan sistem transmisi ini berdampak pada setting pengaman saluran akibat perubahan panjang transmisi dan nilai impedansi. Sebelum dilakukan analisa setting impedansi, Zone jangkauan rele jarak (Distance Relay) dengan arus, waktu kerja dan koordinasi rele OCR (Over Current Relay) terlebih dahulu dilakukan analisa arus gangguan hubung singkat dua phasa dan tiga phasa simetris menggunakan program ETAP PowerStation. Setelah dilakukan perhitungan setting rele jarak, didapat nilai impedansi saluran pada GIS Tanah Lot sebesar $2,4+\mathrm{j}$ 6,96 $\Omega$ dengan setting Zone 1 (80\%): 0,200 + j 0,588 $\Omega$, Zone 2 $(120 \%): 0,30+\mathrm{j} 0,882 \Omega$, dan Zone $3(220 \%): 0,68+\mathrm{j} 2,30 \Omega$. Setting waktu kerja rele OCR (Over Current Relay) ditunjukan waktu tunda rele ( $t D>$ ) untuk GIS Tanah Lot - Antosari dan GIS Tanah Lot - Kapal memiliki nilai 0,48 dengan nilai waktu kerja aktual rele sebesar 1,134 detik.
\end{abstract}

Kata kunci : Rele Jarak, Analisa Hubung Singkat, Rele OCR, ETAP PowerStation.

\section{Abstract}

In an effort to increase electricity supply PT PLN (Persero) build GIS Tanah Lot in Nyitdah Village Tabanan regency. The new GIS development makes the network transmission system High Voltage Air Line $150 \mathrm{kV}$ changed. Changes in this transmission system impact on the channel safety settings due to changes in transmission length and impedance value. Prior to the analysis of the impedance setting, the Distance Relay Distance Zone with current, working time and OCR Relay coordination (Over Current Relay) firstly analyzes short circuit flows two phases and three symmetric phases using ETAP PowerStation program. After calculation of distance relation setting, the value of channel impedance in Tanah Lot GIS is $2,4+j 6,96 \Omega$ with Zone 1 setting (80\%): 0,200 + j 0,588 $\Omega$, Zone 2 (120\%): $0,30+j 0.882 \Omega$, and Zone 3 (220\%): $0.68+j 2.30 \Omega$. OCR (Over Current Relay) release time setting is indicated by releasing delay ( $t D>)$ for Tanah Lot GIS - Antosari and Tanah Lot GIS - The vessel has a value of 0.48 with an actual working time release of 1.134 seconds.

Keywords: Distance Relay, Short Circuit Analysis, Over Current Relay, ETAP PowerStation.

\section{PENDAHULUAN}

Pembangunan daerah tujuan wisata di daerah Tabanan bagian selatan akan dilaksanakan sesuai dengan rencana Pemerintah Kabupaten Tabanan. Banyaknya daerah tujuan wisata yang sedang berkembang di sekitar Pura Tanah Lot menyebabkan pertumbuhan industri dan pariwisata seperti pembangunan hotel-hotel berbintang dan tempat wisata menjadi luas, meluasnya pertumbuhan pembangunan yang terjadi akan berpengaruh juga terhadap pertumbuhan beban listrik yang semakin meningkat.

Selama ini supply listrik di daerah Tabanan bagian Selatan berasal dari G.I 
Kapal yang memiliki jarak cukup jauh sekitar $15 \mathrm{~km}$ dari beban. Jarak supply listrik yang jauh dengan pusat-pusat beban membuat kemungkinan terjadi gangguan cukup besar, guna meningkatkan kontinyuitas keandalan sistem tenaga dan mengurangi gangguan yang terjadi pada jaringan maka dibangun Gas Insulated Switchgear (GIS) di sekitar Tanah Lot agar lebih dekat dengan pusat-pusat beban.

Pembangunan GIS Tanah Lot merubah saluan transmisi $150 \mathrm{kV}$ menjadi lebih pendek, dengan jarak awal $23 \mathrm{~km}$ berubah menjadi $12 \mathrm{~km}$ untuk jarak GI antosari hingga GIS Tanah Lot dan $11 \mathrm{~km}$ untuk jarak GIS Tanah Lot menuju GI Kapal, perubahan jarak tersebut akan mempengaruhi terhadap setting pada pengaman rele jarak dan rele arus lebih.

Pada penelitian ini dilakukan perencanaan setting pengaman rele jarak dan backup setting rele arus lebih pada Saluran Udara Tegangan Tinggi 150 kV GI Antosari - GIS Tanah Lot dan GIS Tanah Lot - GI Kapal yang akan dibangun untuk mendapatkan nilai setting rele jarak dan setting rele OCR yang baik agar dapat mengamankan sistem transmisi guna meningkatkan keandalan sistem jaringan kelistrikan di Bali yang sesuai dengan kententuan PLN.

\section{KAJIAN PUSTAKA}

\subsection{Prinsip Kerja Rele Jarak}

Relai jarak mengukur tegangan pada titik relai dan arus gangguan yang terlihat dari relai, dengan membagi besaran tegangan dan arus [1] menggunakan Persamaan :

$$
Z_{f} \frac{V_{f}}{I_{f}}
$$

\subsection{Penyetelan Daerah Jangkauan pada Rele Jarak}

Rele jarak pada dasarnya bekerja mengukur impadansi saluran, apabila impedansi yang terukur / dirasakan relai lebih kecil impedansi tertentu akibat gangguan $\left(Z_{\text {set }} / Z_{f}\right)$ maka rele akan bekerja [2].

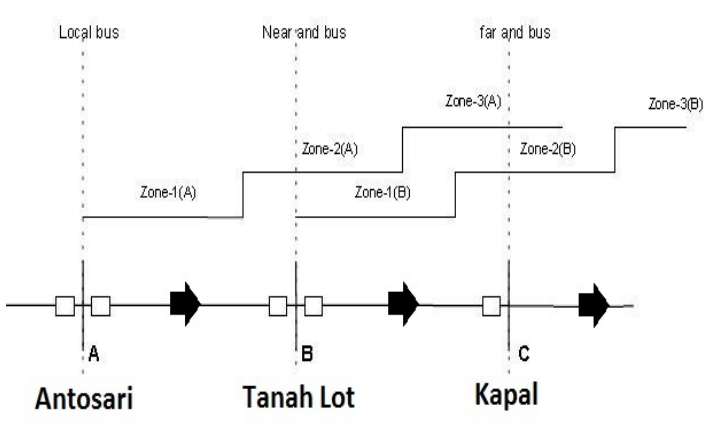

Gambar 1. Daerah penyetelan rele jarak tiga tingkat

Penyetelan rele jarak terdiri dari tiga daerah pengamanan, yaitu: Penyetelan Zone-1 dengan waktu kerja rele $T_{1}$, Zone-2 dengan waktu kerja rele $T_{2}$, dan Zone-3 waktu kerja rele $\mathrm{T}_{3}[3]$.

\subsubsection{Penyetelan Zone-1}

Dengan mempertimbangkan adanya kesalahan-kesalahan dari data saluran, CT, PT, dan peralatan penunjang lain sebesar 10\% - $20 \%$, Zone-1 relai disetel $80 \%$ dari panjang saluran yang diamankan [4] dapat dihitung dengan Persaman :

Zone-1=0.8. $Z_{\mathrm{L} 1}$ (Saluran)

Waktu kerja rele seketika, $\left(T_{1}=0\right)$

\subsubsection{Penyetelan Zone-2}

Prinsip peyetelan Zone-2 dapat diperoleh dengan Persamaan :

$$
\text { Zone- } 2_{\min }=1.2
$$

$\mathrm{Z}_{\mathrm{L} 1 \ldots \ldots \ldots \ldots \ldots \ldots . . . . . . . .(3)}$

$0,8 . Z_{\mathrm{L} 2} \ldots . . .(4)$

$$
\text { Zone- } 2_{\text {mak }}=0.8 \quad . \quad Z_{\mathrm{L} 1}+
$$

Keterangan :

$\mathrm{Z}_{\mathrm{L} 1}=$ Impedansi yang diamankan.

$\mathrm{Z}_{\mathrm{L} 1}=$ Impedansi yang terpendek $(\Omega)$

Waktu kerja relai $\mathrm{T}_{2}=0.4 \mathrm{~s} / \mathrm{d} 0.8 \mathrm{dt}$.

\subsubsection{PeSnyetelan Zone-3}

Prinsip penyetelan Zone-3 dapat diperoleh dengan Persamaan :

$$
\begin{array}{lr}
\begin{array}{l}
\text { Zone- } 3_{\text {min }} \\
\left.. Z_{\mathrm{L} 2}\right) \ldots \ldots \ldots \ldots . .(5) \\
\text { Zone- } 3_{\text {mak1 } 1}=0.8
\end{array} & =1.2 .\left(\mathrm{Z}_{\mathrm{L} 1}+0.8\right. \\
\left.. \mathrm{Z}_{\mathrm{L} 2}\right) \ldots \ldots \ldots . .(6) & \left(\mathrm{Z}_{\mathrm{L} 1}+1.2\right.
\end{array}
$$




\author{
Zone $-3_{\text {mak } 2}=0.8$ \\ .$\left.Z_{\mathrm{TR}}\right) \ldots \ldots \ldots \ldots(7)$ \\ Keterangan : \\ $Z_{\mathrm{L} 1}=$ Impedansi saluran yang diamankan \\ $Z_{\mathrm{L} 2}=$ Impedansi saluran berikutnya yang \\ terpanjang \\ Waktu kerja rele $T_{3}=1.2 \mathrm{~s} / \mathrm{d} 1.6 \mathrm{dt}$.
}

$\left(\mathrm{Z}_{\mathrm{L} 1}+\mathrm{k}\right.$

\subsection{Prinsip Dasar Perhitungan Setting Rele Arus Lebih}

Sebagai dasar pertimbangan untuk menghitung setting arus rele arus lebih adalah dengan memperhatikan dua faktor yaitu arus kerja (pick up) dan arus kembali (drop off) [5], seperti Persamaan :

$$
K_{d} \frac{I_{d}}{I_{p}}
$$

Keterangan :

$\mathrm{K}_{\mathrm{d}}=$ Faktor arus kembali

$I_{d}=$ Arus kembali (arus drop off)

$I_{p}=$ Arus kerja (arus pick up)

\subsubsection{Penyetelan Arus}

Rele arus lebih tidak boleh bekerja pada keadaan beban maksimum. Dalam beberapa hal, arus nominal pada trafo arus (CT) merupakan arus maksimumnya [6], dapat diperoleh dengan Persamaan :

$$
\mathrm{I}_{\text {set }}=\frac{K_{f k}}{K_{d}} \times \mathrm{I}_{\text {nom }}
$$

Keterangan :

$\mathrm{I}_{\text {set }} \quad=$ Setelan arus

$\mathrm{K}_{\mathrm{fk}} \quad=$ Faktor keamanan, mempunyai

nilai $1,1-1,2$

$\mathrm{K}_{\mathrm{d}} \quad=$ faktor arus kembali

$I_{\text {nom }}=$ Arus maksimum yang diijinkan untuk peralatan yang diamankan

\subsubsection{Penyetelan Waktu}

Besarnya arus hubung singkat pada setiap seksi (I), Penyetelan / setting arusnya (Is), Kurva karakteristik rele yang dipakai, Maka waktu tunda (td) [7] dapat dicari dengan Persamaan :

$$
t_{d}=\frac{\left(\frac{I_{f}}{I_{s e t}}\right)^{0.02}-1}{0,14} x t
$$

Keterangan :

$I_{f}=$ Arus gangguan hubung singkat dua phase $\mathrm{t}=$ Waktu kerja rele yang dikehendaki

Waktu aktual rele terhadap gangguan maksimum dapat dicari dengan Persamaan:

$$
t=\frac{0,14}{\left(\frac{I_{f}}{I_{\text {set }}}\right)^{0.02}-1} x t_{d}
$$

Keterangan :

$I_{f}=$ Arus gangguan hubung singkat 3 phase $t_{d}=$ Waktu tunda

\subsection{Penerapan Program ETAP PowerStation \\ ETAP PowerStation adalah soft-} ware untuk power system yang bekerja berdasarkan plant (project). ETAP PowerStation dapat menggambaran single line diagram secara grafis, dengan menyediakan modeling peralatan dan alat-alat pendukung yang berhubungan dengan analisis yang akan dilakukan, misalnya generator, data motor, data kabel, relay, Current Transformer (CT), dan lain-lain.

\section{METODE PENELITIAN}

Analisa dalam penelitian Tugas Akhir ini dilakukan dalam beberapa tahapan sebagai berikut :

1. Metode pengumpulan data-data impedansi penghantar sistem SUTT $150 \mathrm{kV}$ Bali..

2. Analisa nilai impedansi GI Antosari GIS Tanah Lot - GI Kapal dengan menggunakan perhitungan analisa.

3. Perhitungan setting impedansi rele jarak untuk Zone reach, Zone 1 , Zone 2, Zone 3 GI Antosari - GIS Tanah Lot - GI Kapal menggunakan perhitungan analisa.

4. Menampilkan hasil perhitungan nilai setting rele jarak Zone pengaman.

5. Analisa besar arus hubung singkat $\mathrm{GI}$ Antosari - GIS Tanah Lot - GI Kapal dengan menggunakan ETAP PowerStation.

6. Menampilkan hasil perhitungan nilai setting arus dan waktu kerja rele arus lebih GI Kapal - GIS Tanah Lot - GI Kapal. 
Berdasarkan penjelasan tahapan penelitian di atas, alur analisis dapat ditampilkan dalam bentuk flowchart seperti pada Gambar 2 :

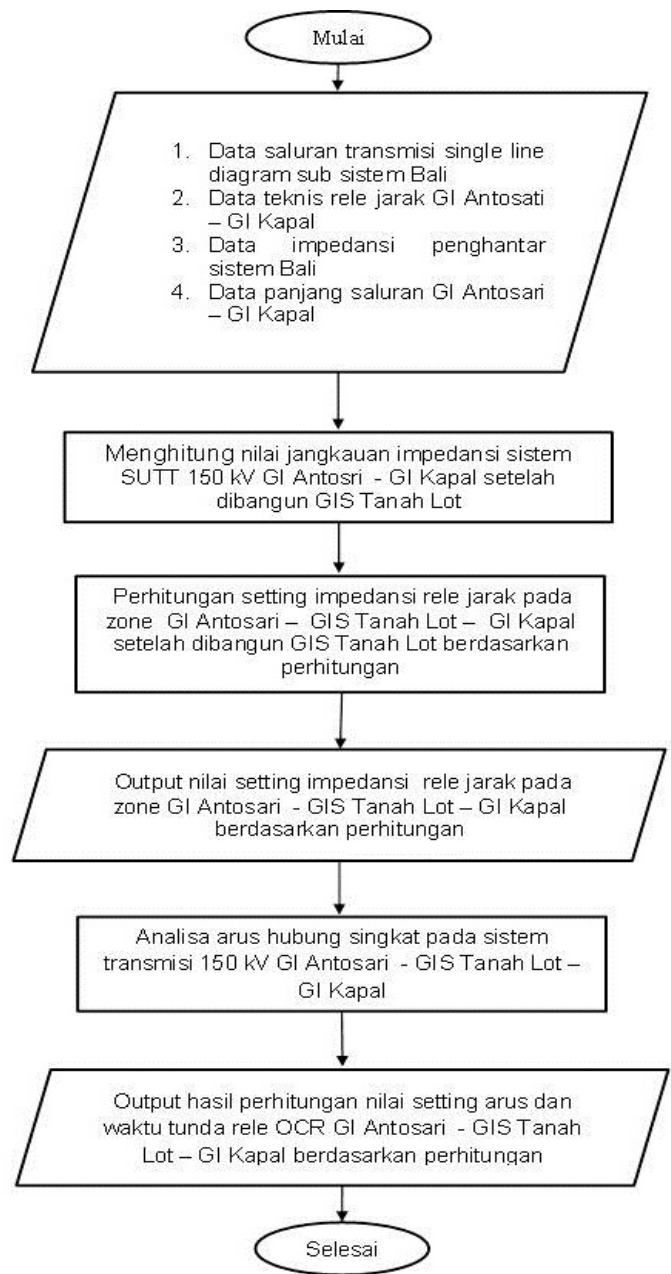

Gambar 2. Alur Analisis Setting Rele Jarak dan Rele Arus Lebih GI Antosari - GIS

Tanah Lot - GI Kapal

\section{HASIL DAN PEMBAHASAN}

\subsection{Impedansi Saluran Karena} Pengaruh Mutual Inductance

\subsubsection{Mutual Inductance Pada Saluran Transmisi GI Antosari - GIS Tanah Lot}

Berdasarkan perhitungan diketahui bahwa impedansi saluran terbesar dengan pangaruh Mutual Inductance terdapat pada saluran transmisi antara GI Kapal - GI Celukan Bawang dengan nilai impedansi total $(Z)$ yang sama yakni $17,07+\mathrm{j} 45,15 \Omega$, sedangkan impedansi terkecil terletak pada saluran transmisi antara GIS Tanah Lot GI Kapal dan arah berbalik GI Kapal - GIS Tanah Lot dengan nilai impedansi total (Z) yakni 2,4 + j 6,96 $\Omega$. Selengkapnya dapat di lihat pada Tabel 1 .

Tabel 1. Impedansi Saluran dengan di Perhitungkan Mutual Inductance

\begin{tabular}{|c|c|c|c|c|}
\hline \multirow{2}{*}{ No } & \multirow{2}{*}{ Gardu Induk } & \multicolumn{3}{|c|}{ Impedansi Saluran $(\Omega)$} \\
\cline { 3 - 5 } & & $\mathbf{Z 1}=\mathbf{Z 2}$ & $\mathbf{Z} 0$ & $\mathbf{Z}$ total \\
\hline $\mathbf{1}$ & Antosari - Tanah Lot 1 & $1,09+\mathrm{j} 3,17$ & $3,4+\mathrm{j} 9.5$ & $7,2+\mathrm{j} 15,8$ \\
\hline $\mathbf{2}$ & Antosari - Tanah Lot 2 & $1,09+\mathrm{j} 3,17$ & $3,4+\mathrm{j} 9.5$ & $7,2+\mathrm{j} 15,8$ \\
\hline $\mathbf{3}$ & Tanah Lot - Antosari 1 & $1,09+\mathrm{j} 3,17$ & $3,4+\mathrm{j} 9.5$ & $7,2+\mathrm{j} 15,8$ \\
\hline $\mathbf{4}$ & Tanah Lot - Antosari 2 & $1,09+\mathrm{j} 3,17$ & $3,4+\mathrm{j} 9.5$ & $7,2+\mathrm{j} 15,8$ \\
\hline $\mathbf{5}$ & Antosari - Negara 1 & $3,0+\mathrm{j} 8,75$ & $9,6+\mathrm{j} 26.3$ & $15,6+\mathrm{j} 43,8$ \\
\hline $\mathbf{6}$ & Antosari - Negara 2 & $3,0+\mathrm{j} 8,75$ & $9,6+\mathrm{j} 26.3$ & $15,6+\mathrm{j} 43,8$ \\
\hline $\mathbf{7}$ & Tanah Lot - Kapal 1 & $0,47+\mathrm{j} 1,38$ & $1,5+\mathrm{j} 4.2$ & $2,4+\mathrm{j} 6,96$ \\
\hline $\mathbf{8}$ & Tanah Lot - Kapal 2 & $0,47+\mathrm{j} 1,38$ & $1,5+\mathrm{j} 4.2$ & $2,4+\mathrm{j} 6,96$ \\
\hline $\mathbf{9}$ & Kapal - Tanah Lot 1 & $0,47+\mathrm{j} 1,38$ & $1,5+\mathrm{j} 4.2$ & $2,4+\mathrm{j} 6,96$ \\
\hline $\mathbf{1 0}$ & Kapal - Tanah Lot 2 & $0,47+\mathrm{j} 1,38$ & $1,5+\mathrm{j} 4.2$ & $2,4+\mathrm{j} 6,96$ \\
\hline $\mathbf{1 1}$ & Kapal - Gianyar 1 & $1,3+\mathrm{j} 3,80$ & $4,18+\mathrm{j} 11,4$ & $6,78+\mathrm{j} 19$ \\
\hline $\mathbf{1 2}$ & Kapal - Gianyar 2 & $1,3+\mathrm{j} 3,80$ & $4,18+\mathrm{j} 11,4$ & $6,78+\mathrm{j} 19$ \\
\hline $\mathbf{1 3}$ & $\begin{array}{r}\text { Kapal - Pemecutan } \\
\text { Kelod 1 }\end{array}$ & $0,6+\mathrm{j} 2,22$ & $2,26+\mathrm{j} 6,7$ & $3,46+\mathrm{j} 11,14$ \\
\hline $\mathbf{1 4}$ & $\begin{array}{r}\text { Kapal - Pemecutan } \\
\text { Kelod 2 }\end{array}$ & $0,6+\mathrm{j} 2,22$ & $2,26+\mathrm{j} 6,7$ & $3,46+\mathrm{j} 11,14$ \\
\hline $\mathbf{1 5}$ & $\begin{array}{r}\text { Kapal - } \\
\text { Celukanbawang 1 }\end{array}$ & $2,2+\mathrm{j} 9,03$ & $12,67+\mathrm{j} 27,09$ & $17,07+\mathrm{j} 45,15$ \\
\hline $\mathbf{1 6}$ & $\begin{array}{r}\text { Kapal - } \\
\text { Celukanbawang 2 }\end{array}$ & $2,2+\mathrm{j} 9,03$ & $12,67+\mathrm{j} 27,09$ & $17,07+\mathrm{j} 45,15$ \\
\hline & & & & \\
\hline
\end{tabular}

\subsection{Analisa Perhitungan Zone dan Setting Rela Jarak}

Pada perhitungan setting rele jarak didapat nilai terbesar pada saluran transmisi GI Antosari - GIS Tanah Lot - GI Kapal dengan nilai impedansi rele jarak pada Zone 1 (80\%) adalah 0,872 + j 2,536 (primer) dan 0,46 + j 1,351 (sekunder) dengan waktu kerja seketika (0s), nilai impedansi rele jarak pada Zone 2 (120\%) adalah $1,30+\mathrm{j} 3,804$ (primer) dan $0,69+\mathrm{j}$ 2,027 (sekunder) dengan waktu kerja 0,4 detik, dan nilai impedansi rele jarak pada Zone 3 (220\%) adalah 1,87 + j 5,46 (primer) dan $0,99+j 2.910$ (sekunder) dengan waktu kerja 1,2 detik. Hasil selengkapnya dapat dilihat pada Tabel 2. 


\subsection{Analisa Arus Hubung Singkat}

Analisa hubung singkat yang terjadi sebelum dan setelah dibangunnya GIS Tanah Lot dianalisa dengan menggunakan software ETAP, hasil analisa dapat dilihat pada Tabel 3.

Tabel 2. Setting Rele Jarak GI Antosari GIS Tanah Lot - GI Kapal Arah Load Flow

\begin{tabular}{|c|c|c|c|c|c|c|c|c|c|c|}
\hline \multirow{4}{*}{$\mathrm{N}$} & \multirow{4}{*}{$\begin{array}{l}\text { Gardu } \\
\text { Induk }\end{array}$} & \multicolumn{9}{|c|}{ Setting Rele Jarak } \\
\hline & & \multirow{2}{*}{\multicolumn{2}{|c|}{$\begin{array}{c}\text { Zone } 1 \\
80 \%\end{array}$}} & \multirow{3}{*}{ (s) } & \multirow{2}{*}{\multicolumn{2}{|c|}{$\begin{array}{c}\text { Zone } 2 \\
120 \%\end{array}$}} & \multirow{3}{*}{$\begin{array}{l}\text { T2 } \\
\text { (s) }\end{array}$} & \multirow{2}{*}{\multicolumn{2}{|c|}{\begin{tabular}{|l|} 
Zone 3 \\
$220 \%$
\end{tabular}}} & \multirow{3}{*}{$\begin{array}{l}\text { T3 } \\
\text { (s) }\end{array}$} \\
\hline & & & & & & & & & & \\
\hline & & Primer & Secunder & & \begin{tabular}{|l|} 
Primer \\
\end{tabular} & Secunder & & \begin{tabular}{|l|} 
Primer \\
\end{tabular} & Secunder & \\
\hline 1 & $\begin{array}{l}\text { Antosari- } \\
\text { Tanah Lot } \\
\text { - Kapal } 1\end{array}$ & $\begin{array}{l}0,872+ \\
j 2,536\end{array}$ & $\begin{array}{c}0,46+j \\
1,351\end{array}$ & 0 & $\begin{array}{c}1,30+j \\
3,804\end{array}$ & $\begin{array}{c}0,69+j \\
2,027\end{array}$ & 0,4 & $\begin{array}{c}1,87+j \\
5,46\end{array}$ & $\begin{array}{c}0,99+j \\
2.910\end{array}$ & 1,2 \\
\hline 2 & $\begin{array}{l}\text { Antosari- } \\
\text { Tanah Lot } \\
\text { - Kapal } 2\end{array}$ & $\begin{array}{l}0,872+ \\
j 2,536\end{array}$ & $\begin{array}{c}0,46+j \\
1,351\end{array}$ & 0 & $\begin{array}{c}1,30+j \\
3,804\end{array}$ & $\begin{array}{c}0,69+j \\
2,027\end{array}$ & 0,4 & $\begin{array}{c}1,87+j \\
5,46\end{array}$ & $\begin{array}{c}0,99+j \\
2.910\end{array}$ & 1,2 \\
\hline 3 & $\begin{array}{l}\text { Tanah Lot } \\
\text { - Antosari } \\
\text { - Negara } 1\end{array}$ & $\begin{array}{l}0,872+ \\
j 2,536\end{array}$ & $\begin{array}{c}0,46+j \\
1,351\end{array}$ & 0 & $\begin{array}{c}1,30+j \\
3,804\end{array}$ & $\begin{array}{c}0,69+j \\
2,027\end{array}$ & 0,4 & $\begin{array}{c}1,30+j \\
3,804\end{array}$ & $\begin{array}{c}0,69+j \\
2,027\end{array}$ & 1,2 \\
\hline 4 & $\begin{array}{l}\text { Tanah Lot } \\
\text { - Antosari } \\
\text { - Negara } 2\end{array}$ & $\begin{array}{l}0,872+ \\
j 2,536\end{array}$ & $\begin{array}{c}0,46+j \\
1,351\end{array}$ & 0 & $\begin{array}{c}1,30+j \\
3,804\end{array}$ & $\begin{array}{c}0,69+j \\
2,027\end{array}$ & 0,4 & $\begin{array}{c}1,30+j \\
3,804\end{array}$ & $\begin{array}{c}0,69+j \\
2,027\end{array}$ & 1,2 \\
\hline 5 & $\begin{array}{c}\text { Tanah lot - } \\
\text { Kapal - } \\
\text { P.Kelod } 1\end{array}$ & $\begin{array}{l}0,376+ \\
j 1,104\end{array}$ & $\begin{array}{c}0,200+j \\
0,588\end{array}$ & 0 & $\begin{array}{c}0,56+j \\
1,656\end{array}$ & $\begin{array}{c}0,30+j \\
0,882\end{array}$ & 0,4 & $\begin{array}{c}1,28+j \\
4,32\end{array}$ & $\begin{array}{c}0,68+j \\
2.30\end{array}$ & 1,2 \\
\hline 6 & $\begin{array}{c}\text { Tanah lot - } \\
\text { Kapal - } \\
\text { P.Kelod } 2\end{array}$ & $\begin{array}{l}0,376+ \\
j 1,104\end{array}$ & $\begin{array}{c}0,200+j \\
0,588\end{array}$ & 0 & $\begin{array}{c}0,56+j \\
1,656\end{array}$ & $\begin{array}{c}0,30+j \\
0,882\end{array}$ & 0,4 & $\begin{array}{c}1,28+j \\
4,32\end{array}$ & $\begin{array}{c}0,68+j \\
2.30\end{array}$ & 1,2 \\
\hline 7 & $\begin{array}{c}\text { Tanah lot - } \\
\text { Kapal - } \\
\text { Gianyar } 1\end{array}$ & $\begin{array}{l}0,376+ \\
j 1,104\end{array}$ & $\begin{array}{c}0,200+j \\
0,588\end{array}$ & 0 & $\begin{array}{c}0,56+j \\
1,656\end{array}$ & $\begin{array}{c}0,30+j \\
0,882\end{array}$ & 0,4 & $\begin{array}{c}2,12+j \\
6,21\end{array}$ & $\begin{array}{c}1,12+j \\
3.30\end{array}$ & 1,2 \\
\hline 8 & $\begin{array}{c}\text { Tanah lot - } \\
\text { Kapal - } \\
\text { Gianyar } 2\end{array}$ & $\begin{array}{l}0,376+ \\
j 1,104\end{array}$ & $\begin{array}{c}0,200+j \\
0,588\end{array}$ & 0 & $\begin{array}{c}0,56+j \\
1,656\end{array}$ & $\begin{array}{c}0,30+j \\
0,882\end{array}$ & 0,4 & $\begin{array}{c}2,12+j \\
6,21\end{array}$ & $\begin{array}{c}1,12+j \\
3.30\end{array}$ & 1,2 \\
\hline 9 & $\begin{array}{c}\text { Tanah lot - } \\
\text { Kapal - } \\
\text { Baturi } 1\end{array}$ & $\begin{array}{l}0,376+ \\
j 1,104\end{array}$ & $\begin{array}{c}0,200+j \\
0,588\end{array}$ & 0 & $\begin{array}{c}0,56+j \\
1,656\end{array}$ & $\begin{array}{c}0,30+j \\
0,882\end{array}$ & 0,4 & $\begin{array}{l}10,36+ \\
j 20,33\end{array}$ & $\begin{array}{c}5,52+j \\
10.83\end{array}$ & 1,2 \\
\hline 10 & $\begin{array}{c}\text { Tanah lot - } \\
\text { Kapal - } \\
\text { Payangan } \\
1\end{array}$ & $\begin{array}{l}0,376+ \\
j 1,104\end{array}$ & $\begin{array}{c}0,200+j \\
0,588\end{array}$ & 0 & $\begin{array}{c}0,56+j \\
1,656\end{array}$ & $\begin{array}{c}0,30+j \\
0,882\end{array}$ & 0,4 & $\begin{array}{c}4,75+j \\
9,63\end{array}$ & $\begin{array}{c}2,53+j \\
5.13\end{array}$ & 1,2 \\
\hline
\end{tabular}

Tabel 3. Hasil Analisa Hubung Singkat dengan Program ETAP sebelum dan setelah dibangunnya GIS Tanah Lot

\begin{tabular}{|c|c|c|c|c|c|}
\hline \multirow{2}{*}{ No } & \multirow{2}{*}{ GI } & \multicolumn{2}{|c|}{ Sebelum } & \multicolumn{2}{c|}{ Sesudah } \\
\cline { 3 - 6 } & Gangguan & Arus & Arus & Arus & Arus \\
Gangguan 3 & Gangguan 2 \\
Phasa (A) & Phasa (A) & $\begin{array}{c}\text { Gangguan 3 } \\
\text { Phasa (A) }\end{array}$ & $\begin{array}{c}\text { Gangguan 2 } \\
\text { Phasa (A) }\end{array}$ \\
\hline $\mathbf{1}$ & Negara & 8.038 & 6.972 & 7.671 & 6.652 \\
\hline $\mathbf{2}$ & Antosari & 10.645 & 9.238 & 9.137 & 7.924 \\
\hline $\mathbf{3}$ & Tanah Lot & - & - & 12.613 & 10.943 \\
\hline $\mathbf{4}$ & Kapal & 17.614 & 15.317 & 17.830 & 15.504 \\
\hline
\end{tabular}

\subsection{Penyetelan Rele Arus lebih Setelah Masuknya GIS Tanah Lot}

\subsubsection{Penyetelan Rele di Bus Kopel}

a) Penentuan setelan bus kopel GIS Tanah Lot

Ratio trafo arus (CT) : 2000/1

Setelan rele arus lebih (Over Current Relay) menggunakan Persamaan (9).

Sehingga :

$$
\begin{aligned}
I_{\text {set }}= & \frac{1.1}{1} \times 2000 \mathrm{~A} \\
I_{\text {set }}= & 2200 \mathrm{~A} \text { (primer) } \\
I_{\text {set }}= & \frac{2200}{2000} \times 1 \mathrm{~A} \\
I_{\text {set }}= & 1.1 \mathrm{~A} \quad \text { (sekunder } / \text { setelan } \\
& \text { pada rele) }
\end{aligned}
$$

waktu kerja dari rele arus lebih transmisi diharapkan sebesar $\mathrm{t}=1.2$ detik [8]. Sehingga waktu tunda dapat dicari dengan Persamaan (10) :

Sehingga didapat hasil :

$$
t_{d}=0,27
$$

Jadi waktu kerja aktual rele menggunakan Persamaan (11):

Sehingga didapat hasil :

$$
t=1,063 \text { detik }
$$

Perhitungan setelan arus dan waktu kerja rele arus lebih pengaman bus kopel pada GI Antosari dan GI Kapal dapat dicari menggunakan cara yang sama, hasil selengkapnya dapat dilihat pada Tabel 4 dibawah ini.

Tabel 4. Hasil Perhitungan Manual Setting Arus dan Waktu Rele di Bus Kopel

\begin{tabular}{|c|c|c|c|c|c|c}
\hline \multirow{2}{*}{ No } & \multirow{2}{*}{$\begin{array}{c}\text { Gardu } \\
\text { Induk }\end{array}$} & $\begin{array}{l}\text { Inom } \\
\text { Relay }\end{array}$ & \multirow{2}{*}{ CT Rasio } & \multicolumn{3}{|c}{ Hasil Setting } \\
\cline { 5 - 8 } & & & & I> (Ampere) & $\begin{array}{c}\text { td }> \\
\text { (SI) }\end{array}$ & $\begin{array}{c}\text { Waktu } \\
\text { Kerja } \\
\text { (detik) }\end{array}$ \\
\hline $\mathbf{1}$ & Antosari & $1 \mathrm{~A}$ & $1000 / 1$ & $1.1=1100$ & 0,34 & 1,100 \\
\hline $\mathbf{2}$ & Tanah Lot & $1 \mathrm{~A}$ & $2000 / 1$ & $1.1=2200$ & 0,27 & 1,063 \\
\hline 3 & Kapal & $1 \mathrm{~A}$ & $2000 / 1$ & $1.1=2200$ & 0,34 & 1,132 \\
\hline
\end{tabular}

\subsubsection{Penyetelan Rele Pada Setiap Saluran}

a) Setting rele OCR pada saluran GI Antosari-GIS Tanah Lot Ratio trafo arus (CT) : 800/1

Setting rele arus lebih (Over Current Relay) menggunakan Persamaan (9). Sehingga : 


$$
\begin{aligned}
I_{\text {set }}= & \frac{1.1}{1} \times 646 \mathrm{~A} \\
I_{\text {set }}= & 710 \mathrm{~A} \text { (primer) } \\
I_{\text {set }}= & \frac{710}{800} \times 1 \mathrm{~A} \\
I_{\text {set }}= & 0.89 \mathrm{~A} \text { (sekunder / setelan } \\
& \text { rele) }
\end{aligned}
$$

waktu kerja dari rele arus lebih transmisi diharapkan sebesar $\mathrm{t}=1.2$ detik [8]. Sehingga waktu tunda dapat dicari dengan Persamaa (10) :

Didapat hasil :

$$
t_{d}=0,42
$$

Jadi waktu kerja aktual rele menggunakan Persamaan (11):

Sehingga didapat hasil :

$$
t=1,121 \text { detik }
$$

Setting arus dan waktu kerja rele arus lebih pengaman saluran pada GIS

\begin{tabular}{|c|c|c|c|c|c|c|c|}
\hline \multirow[b]{2}{*}{ No } & \multirow[b]{2}{*}{$\begin{array}{l}\text { Gardu } \\
\text { Induk }\end{array}$} & \multirow[b]{2}{*}{ T/L Bay } & \multirow[b]{2}{*}{$\begin{array}{l}\text { I nom } \\
\text { Relay }\end{array}$} & \multirow[b]{2}{*}{$\begin{array}{c}\text { CT } \\
\text { Rasio }\end{array}$} & \multicolumn{3}{|c|}{ Hasil Setting } \\
\hline & & & & & $\mid>$ (Ampere) & $\begin{array}{l}t d\rangle \\
(S I)\end{array}$ & $\begin{array}{l}\text { Waktu } \\
\text { Kerja } \\
\text { (detik) }\end{array}$ \\
\hline 1 & Antosari & Tanah Lot 1 & $1 \mathrm{~A}$ & $800 / 1$ & $0,89=710$ & 0,42 & 1,121 \\
\hline 2 & Antosari & Tanah Lot 2 & $1 \mathrm{~A}$ & $800 / 1$ & $0,89=710$ & 0,42 & 1,121 \\
\hline 3 & Tanah Lot & Antosari 1 & $1 \mathrm{~A}$ & $800 / 1$ & $0,89=710$ & 0.48 & 1,134 \\
\hline 4 & Tanah Lot & Antosari 2 & $1 \mathrm{~A}$ & $800 / 1$ & $0,89=710$ & 0.48 & 1,134 \\
\hline 5 & Tanah Lot & Kapal 1 & $1 \mathrm{~A}$ & $800 / 1$ & $0,89=710$ & 0.48 & 1,134 \\
\hline 6 & Tanah Lot & Kapal 2 & $1 \mathrm{~A}$ & $800 / 1$ & $0,89=710$ & 0.48 & 1,134 \\
\hline 7 & Kapal & Tanah Lot 1 & $1 \mathrm{~A}$ & $800 / 1$ & $0,89=710$ & 0,54 & 1,135 \\
\hline 8 & Kapal & Tanah Lot 2 & $1 \mathrm{~A}$ & $800 / 1$ & $0,89=710$ & 0,54 & 1,135 \\
\hline
\end{tabular}
Tanah Lot - GI Kapal dapat dicari menggunakan cara yang sama. Hasil dapat dilihat pada Tabel 5 dibawah ini.

Tabel 5. Hasil Perhitungan Manual Setting Arus dan Waktu Rele pada Saluran GI Antosari - GIS Tanah Lot - GI Kapal

\section{SIMPULAN}

1) Setting Zone dan setting rele jarak $\mathrm{GI}$ Antosari sebelum dibangunnya GIS Tanah Lot 1 menunjukan Zone 1 (80\%) pada GI Antosari, Zone 2 (120\%) pada GI Kapal, dan Zone 3 (220\%) pada GI Celukan bawang dengan nilai setting rele Zone $1: 4.416 \Omega$, Zone $2: 6.624$ $\Omega$, Zone 3 : $18.627 \Omega$. Setelah dibangunnya GIS Tanah Lot terdapat perubahan pada Zone dan setting rele jarak GI Antosari 1, dimana Zone 1 (80\%) pada GI Antosari, Zone 2 (120\%) pada GIS Tanah Lot, Zone 3 (220\%) pada GI Kapal dengan nilai setting rele Zone $1: 0,46+\mathrm{j} 1,351 \Omega$, Zone $2: 0,69$ + j 2,027 $\Omega$, Zone $3: 0,99+\mathrm{j} 2.910 \Omega$.

2) Pasca beroperasinya GIS Tanah Lot terjadi perubahan nilai arus hubung singkat pada GI Antosari yang sebelumnya 10.645 A menjadi 9.137 A pada gangguan hubung singkat 3 phasa.

3) Sebelum dibangunnya GIS Tanah Lot, hasil setting arus dan waktu pada GI Antosari - GI Kapal 760 A (primer), 0,95 (sekunder) dan time dial 0,5 s. Setelah Dibangunnya GIS Tanah Lot didapat nilai setting 710 A (primer), 0,89 (sekunder) dan time dial 0,42 s.

\section{DAFTAR PUSTAKA}

[1] Ridwan, A., Dyana, I.G., Arta, I.W., 2015. Studi Pengaruh Mutual Inductance Terhadap setting Rele Jarak pada Saluran Transmisi Double Circuit 150 kV Antara Gl Kapal - GI Pemecutan Kelod. E-Journal SPEKTRUM. 2(3). 106-110.

[2] Horowitz, S. H., Phadked, A.G. 2014. Power System Relaying, 4th edn. John Wiley and Sons Ltd.

[3] Hadianto, A.B., Dyana, I.G., Setiawan, W. 2016. Studi perhitungan relay jarak pada saluran double circuit dengan single conductor antara GI Kapal - GI Pemecutan Kelod menggunakan Artificial Neural Network (ANN). Jurnal Teknologi Elektro. 15(2). 59-66.

[4] PLN (Persero), PT. 2006. Pelatihan Perhitungan Relai dan Scanning. Sidoarjo : PT PLN (Persero) P3B JB Region Jawa Timur dan Bali.

[5] Agung, B.U., Dyana, I.G., Indra, P.G. 2017. Studi Analisis Koordinasi Over Current Relay (OCR) dan Ground Fault Relay (GFR) pada Recloser di Saluran Penyulang Penebel. Jurnal Teknologi Elektro. 16(2). 37-42.

[6] Arismunandar, A ; Kuwahara, S. 2004. Teknik Tenaga Listrik (JILID II). Jakarta : PT Pradnya Paramita.

[7] Susi, I.P, Mujahidin, M., Rozeff, P., 2014. Studi Kasus Beban Lebih 
Terhadap Kinerja Relai Arus Lebih Pada Transformator Daya di Gardu Induk Batu Besar PT. PLN Batam. Jurusan Teknik Elektro, Fakultas

[8] Akhmad Jamaah. 2014. Evaluasi setting rele jarak Gardu Induk Ungaran jaringan 150 kV arah Krapyak 2. Jurnal Orbith, Elektro Politeknik - Semarang. 10(1). 82-89.

[9] Hamdadi, A., Fikriansyah. 2014. Analisa dan pengaturan ulang relai jarak pada saluran udara tegangan tinggi 150 kV Keramasan - Bukit Asam. Jurnal Mikrotiga, Elektro sistem tenaga listrik. 1(3). 9-17.

[10] Stanley, H. Horowitz. Arun G, P. 2008. Power System Relaying, 3rd edn. Research Studies Press Limited. 